\section{Revista}

Ibero-Americana

de Estratégı

\title{
A LOGÍSTICA NA INTERNACIONALIZAÇÃO DOS PORTOS MARÍTIMOS
}

\section{Pedro Picaluga Nevado}

ISEG - Universidade Técnica de Lisboa

E-mail: pnevado@iseg.utl.pt (Portugal)

\section{José Miguel Soares}

ISEG - Universidade Técnica de Lisboa

E-mail: josesoares@iseg.utl.pt (Portugal) 


\section{A LOGÍSTICA NA INTERNACIONALIZAÇÃO DOS PORTOS MARÍTIMOS}

\section{RESUMO}

Como é que um porto marítimo pode ser crescentemente competitivo? Este artigo, conceptual, parte da logística para aproximar os portos dos seus potenciais clientes, especialmente, as empresas exportadoras nacionais e as empresas multinacionais. Acompanhar as movimentações estratégicas dos potenciais clientes é o principal impulsionador da internacionalização dos portos. Com base nesta proposta enquadrada pela globalização e pela confluência entre a logística e as estratégias corporate internacionais, concluímos com cinco proposições mais detalhadas para a competitividade dos portos.

Palavras-chave: Estratégia; Internacionalização.

Revista Ibero-Americana de Estratégia - RIAE, São Paulo, v. 8, n. 2, p. 135-160, jul./dez. 2009. 


\section{INTRODUÇÃO}

Do que se tem escrito sobre a riqueza explorada e inexplorada da costa atlântica lusobrasileira ressalta a possibilidade, por exemplo, de transformar a faixa marítima portuguesa na frente marítima europeia que pode servir portugueses e brasileiros. O problema que trata este artigo é o de tentar melhor compreender como é que a frente marítima atlântica portuguesa e brasileira, sob o ponto de vista da logística, pode tornar ambos os países mais competitivos e como é que os portos se encaixam nesse desígnio estratégico.

Os medos antigos acerca da monstruosidade das grandes empresas, especialmente, multinacionais, pelas suas subsidiárias tentaculares e pelo poder que geriam e controlavam, deram lugar ao reconhecimento da eficiência e competitividade baseada no tamanho e na flexibilidade. As forças impulsionadoras da globalização provocam um inevitável realinhamento de processos competitivos entre muitas indústrias e serviços, forçando as organizações, tais como os portos por exemplo, a abandonar uma postura mais nacionalista e a implementar estratégias internacionais.

Por outro lado, existem crescentes preocupações, ao nível ambiental por exemplo, entre os Estados-Nação mais evoluídos no sentido da despoluição e da menor contaminação atmosférica com dióxido de carbono. Paradoxalmente, assiste-se, em termos estatísticos, ao grande aumento do transporte rodoviário no peso global das cargas transportadas dentro da Europa. É o caso óbvio entre Portugal e Espanha em que as trocas entre países são quase totalmente dominadas, em mais de $90 \%$, pela via terrestre rodoviária ${ }^{1}$. Significa isto que, sendo a Europa o principal destino das exportações portuguesas e um dos mercados mais atractivos para as exportações brasileiras, o papel dos portos poderá ser potenciado em função da interoperabilidade logística e modal. Assim sendo, conhecer as movimentações estratégicas dos potenciais clientes dos portos e não cair em alguma armadilha estratégica de privilegiar infraestruturas esquecendo os clientes, os processos e as limitações financeiras do país ajudará à competitividade das infraestruturas portuárias.

Neste sentido este artigo tenta analisar a competitividade dos portos, na óptica estratégica, pela aproximação dos portos aos seus clientes que são maioritariamente empresas que praticam negócios internacionais. Assim, começa-se por fazer o enquadramento teórico na confluência entre a logística e a internacionalização, focando especialmente a vertente da globalização. Em seguida, e por ser este um artigo conceptual, estabelecem-se cinco proposições de investigação a partir da

\footnotetext{
${ }^{1}$ Programa de Acção Comunitária - Rede Europeia De Transportes 2007-2013.
} 
análise feita à aproximação dos portos aos clientes pelo alinhamento com as movimentações estratégicas internacionais destes. Seguidamente o artigo conclui com algumas considerações finais.

\section{GLOBALIZAÇÃO}

A globalização dos mercados trouxe consigo uma série de transformações, umas mais lentas outras mais rápidas, com impacto na vida de todos nós. No século XX, concretamente até à década de sessenta, a transformação pelo crescimento era uma consequência natural da expansão das economias e das empresas. Na década de setenta, pós 73, a transformação deu-se para fazer face a uma situação de crise, pela necessidade de racionalização e de segurança. Na década de oitenta, a transformação foi pela selecção, de maneira a que as empresas se fossem libertando de negócios não correlacionados com a sua actividade principal e concentrassem a maioria dos recursos no seu core business. Desde então e como se vê no Quadro 1, a globalização tem gerado significativas consequências para as empresas em diferentes dimensões.

As regras da competição global mudaram muito desde os anos 80 do século passado e sem dúvida que continuarão a mudar. Como os tentáculos das empresas envolvem variados locais e negócios, todas essas actividades tornaram-se difíceis de uniformizar e a falta duma superestrutura institucional para os negócios e crescimento internacional revela-se evidente, embora, como referem Fawcett e Magnan (2002) poucas empresas consigam atingir a integração total, provavelmente devido às dificuldades para conseguirem uma efectiva colaboração entre todos os envolvidos. De qualquer modo, a não existência dum governo mundial e a existência de poucas normas globais, não obstante o poder das poucas instituições internacionais que tentam sancionar as actividades internacionais em todo o mundo, permitem evidenciar a falta dum enquadramento normativo para guiar as acções das multinacionais (MNCs).

Revista Ibero-Americana de Estratégia - RIAE, São Paulo, v. 8, n. 2, p. 135-160, jul./dez. 2009. 


\begin{tabular}{|c|c|c|c|}
\hline GEOPOLÍTICAS & SOCIOCULTURAIS & $\begin{array}{l}\text { ECONÓMICA- } \\
\text { EMPRESARIAIS }\end{array}$ & $\begin{array}{c}\text { MOVIMENTAÇÕES } \\
\text { ESTRATÉGICAS }\end{array}$ \\
\hline $\begin{array}{l}\text { 1. As empresas } \\
\text { mais } \\
\text { internacionalizadas } \\
\text { tentam redefinir } \\
\text { em seu proveito as } \\
\text { regras do jogo } \\
\text { impostas numa } \\
\text { fase anterior pelos } \\
\text { Estados-Nação } \\
\text { 2. Esbatimento de } \\
\text { fronteiras }\end{array}$ & $\begin{array}{l}\text { 1. "Mcdonaldização" } \\
\text { e } \\
\text { "Modelo Global de } \\
\text { Modernidade" } \\
\text { (Boyer, 1998) }\end{array}$ & $\begin{array}{l}\text { 1. Novas condições de } \\
\text { concorrência e alargamento } \\
\text { dos mercados. Intensificação } \\
\text { das relações económicas } \\
\text { 2. Desenvolvimento dos } \\
\text { sistemas de comunicação } \\
\text { 3. Redução do ciclo de vida } \\
\text { dos produtos. Lançamento de } \\
\text { produtos para o mercado } \\
\text { mundial } \\
\text { 4. Uniformização de gostos, } \\
\text { padrões de consumo e modos } \\
\text { de vida. Reforço da } \\
\text { normalização } \\
\text { 5. Maior importância dos } \\
\text { factores complexos de } \\
\text { competitividade (Moda, } \\
\text { Design, Imagem de marca,...) } \\
\text { 6. Redes Mundiais } \\
\text { 7. Tecnoglobalismo (Boyer, } \\
\text { 1998) }\end{array}$ & $\begin{array}{l}\text { 1. Comércio Internacional } \\
\text { cresce, desde os anos } 80 \text {, } \\
\text { mais depressa que a } \\
\text { produção } \\
\text { 2. Investimento Directo no } \\
\text { Estrangeiro com um } \\
\text { desenvolvimento } \\
\text { precedentes } \\
\text { 3. Internacionalização dos } \\
\text { mercados financeiros } \\
\text { 4. Implantação triádica } \\
\text { (Ohmae, 1990) } \\
\text { 5. Domínio de sectores- } \\
\text { chave } \\
\text { 6. Concentração estratégica } \\
\text { (fusões e aquisições) } \\
\text { 7. Acordos de Cooperação }\end{array}$ \\
\hline
\end{tabular}

Quadro 1- Consequências da Globalização.

Fonte: Elaborada pelos autores.

Por isso, para o bom e para o mau, o principal árbitro no mercado global é o consumidor, o cliente, e existem poucas sanções visíveis para a introdução de novas regras, sejam elas desagradáveis ou não, na competição.

Como se conclui facilmente da figura acima, em muitas das suas consequências o multinacionalismo, em geral, parece ter vindo para ficar. Como principais agentes deste multinacionalismo, as firmas globais precisam de líderes com visão de entabular um caminho estratégico através de políticas complexas dum mundo fragmentado. A opção pela obtenção de economias de escala encorajou as empresas a serem globais, a estandardizarem os bens produzidos, a padronizar um modelo de modernidade centrado na sociologia cultural americana.

No entanto esta lógica inicial de Levitt (1983) de vender por toda a parte a mesma coisa, da mesma maneira, numa forma de gestão totalmente integrada à escala mundial (Ohmae, 1990) foi sendo complementada em outros diferentes sentidos mais complexos. Efectivamente, em muitas indústrias essas economias de escala falharam, em parte devido à pressão da costumização, parcialmente devido a barreiras logísticas e a custos de transportes a partir de fábricas centralmente 
localizadas em face dos dispersos consumidores e parcialmente, também, devido a gostos cada vez mais individuais. As firmas, por outro lado, também respondem ao mercado global constituindo acordos colaborativos e jointventures com múltiplos parceiros. À medida que a globalização avança e à medida que as mudanças vão ocorrendo, cada vez mais empresas vão procurando e encontrando parceiros com estratégias semelhantes forçando uma rede também ela estrategicamente similar (Hitt, Ireland, \& Hoskisson, 2005). A sua competitividade vai para além da empresa e dependerá, então, largamente das capacidades de aprofundar e fortalecer as redes cooperativas perante outras redes constituídas pelos seus competidores.

A matriz global de pensamento, essencial para a sobrevivência na competição global, passa pela habilidade da empresa em se transformar continuamente (Tichy, Brimm, Charan, \& Takeuchi, 1993), em operar globalmente com equipas que saibam resolver e ultrapassar problemas de culturas diferentes (Bartlett \& Ghoshal, 2000), em ter a capacidade de transformar ameaças em oportunidades, de motivar as pessoas para a excelência e superação, de introduzir inovações no mercado a ritmo constante e rápido, de adquirir e gerir conhecimento existente em qualquer parte do mundo (Doz, Santos, \& Williamson, 2001), de desenvolver indivíduos e transformar a organização para os negócios, em geral.

Em suma, assiste-se à internacionalização de um cada vez maior número de empresas e países, que vai gerando crescentes movimentações estratégicas internacionais por parte dessas empresas, nomeadamente movimentos de racionalização, cooperação, concentração e deslocalização de actividades e negócios, assim como uma importância acrescida da logística quer a de curta, média, quer a de longa distância. Por isso a internacionalização dos transportes (portos, incluídos) é uma crescente inevitabilidade ${ }^{2}$ e para ser bem-sucedida deverá passar, também, pela cooperação - intermodalidade ${ }^{3}$ e interoperabilidade - e pela logística. Nos últimos anos tem havido um aumento considerável da movimentação de produtos usando mais de um modo de transporte no processo. Uma das características principais da intermodalidade é a troca directa de equipamentos entre os diferentes modos de transporte (Ballou, 2004). Por exemplo, uma iniciativa importante desta cooperação na Europa é a Rede de Transportes Transeuropeia. O chamado Arco Atlântico, constituído pela área da Europa situada ao largo do Oceano Atlântico e que abrange a Irlanda, algumas regiões do Reino Unido, como a Escócia, a Irlanda do Norte, País de Gales e o sudoeste de Inglaterra, as regiões da costa atlântica de França, as regiões costeiras atlânticas do norte de Espanha, as Ilhas Canárias e a costa de Portugal, incluindo os arquipélagos, é de alguma forma

\footnotetext{
${ }^{2}$ Programa de Acção Comunitária - Rede Europeia De Transportes 2007-2013

3 Transporte intermodal é o transporte de mercadorias numa mesma unidade de carga com utilização de mais do que um modo de transporte (Comunicado da C.E., 2006), sem manipulação das mercadorias.
} 
parte da complementaridade que o espaço de regiões mais ocidentais dos países europeus necessita para a sua integração. Na realidade, este Arco é constituído por um conjunto de regiões muito afastadas, na maioria dos casos, dos principais mercados europeus. Todavia podem ser consideradas regiões privilegiadas para a entrada na Europa dos movimentos de mercadorias e passageiros vindos das Américas e África. Por isso o Arco Atlântico tem um papel determinante para a Europa no que diz respeito ao transporte marítimo, por um lado, e ao combinado e multimodal, por outro. Neste sentido e como sublinha Mateus (2009), mais que uma pequena zona de passagem, a costa atlântica, nomeadamente a portuguesa, tem todas as condições para ser um ponto de amarração relevante das grandes rotas marítimas, que circunscrevem todos os continentes.

No que respeita à logística, as megatendências actuais e futuras descrevem a cooperação e a relação com o cliente como um dos factores da maior importância (Bowersox, Closs, \& Stank, 2000), na mesma linha, aliás, de Prahalad e Ramaswamy (2000), para quem é o cliente quem decide o que se pode e o que não se pode fazer, na medida em que são as características do que é oferecido que dá valor ao produto que o cliente deseja e não a empresa por si só. Como interveniente logístico, os portos funcionam como polos integradores do transporte marítimo nos sistemas multimodais (Menezes, 2000), pelo que a confluência entre a logística dos portos e a multinacionalidade dos seus respectivos clientes aconselha a uma cooperante aproximação entre ambas as partes.

\section{APROXiMAÇÃO AO CliENTE E ALINHAMENTO DOS PORTOS COM OS CLIENTES: PROPOSIÇÕES}

O transporte marítimo é, no mercado global, o modo dominante de transporte de mercadorias (Chopra \& Meindl, 2007), pois, segundo os mesmos autores, levando em linha de conta as quantidades transportadas e as distâncias percorridas, o transporte marítimo é de longe o transporte mais económico. Este facto tem levado a um aumento da procura de barcos cada vez maiores e mais rápidos, de forma a melhorar as economias de escala do transporte em contentores, o que só sucederá com um bom aproveitamento das capacidades dos portos.

Os potenciais clientes dos portos são as empresas nacionais exportadoras, as multinacionais de produção e/ou distribuição de bens, e com uma importância crescente os operadores logísticos internacionais, que trabalham em nome das empresas nacionais e multinacionais. Estes grandes operadores internacionais estão alinhados com as empresas contratantes e estão também alterando o

Revista Ibero-Americana de Estratégia - RIAE, São Paulo, v. 8, n. 2, p. 135-160, jul./dez. 2009. 
A Logística na Internacionalização dos Portos Marítimos

seu comportamento estratégico em face da globalização dos mercados, das redes de transportes internacionais e da necessidade de ganhos de eficiência e valor acrescentado pela via da logística. Como já vimos, o transporte combinado e/ou multimodal é uma emanação da gestão logística no que concerne às redes de transportes transfronteiriças, e, igualmente, a logística emerge mais necessária com a globalização, ajudando à implementação de economias de escala como é o caso da utilização do contentor no transporte marítimo. A crescente importância dos transportadores internacionais deriva do facto de serem empresas que gerem serviços diferentes, em cooperação, ou mesmo por concentração, nomeadamente serviços de armação, trânsito, operação portuária, concessão, postponement ${ }^{4}$ e outros, com um objectivo logístico da maior relevância que é o de controlarem todo o percurso duma mercadoria desde a origem, em regra a empresa cliente contratante, ao destino final.

Em suma, a aproximação aos clientes pode ser feita ou através destes grandes operadores que integram o negócio portuário nas operações logísticas globais, ou através das próprias empresas produtoras contratantes dos operadores - em regra multinacionais - como se vê na Figura 1.

Figura 1- O Negócio Portuário E A Aproximação Ao Cliente.

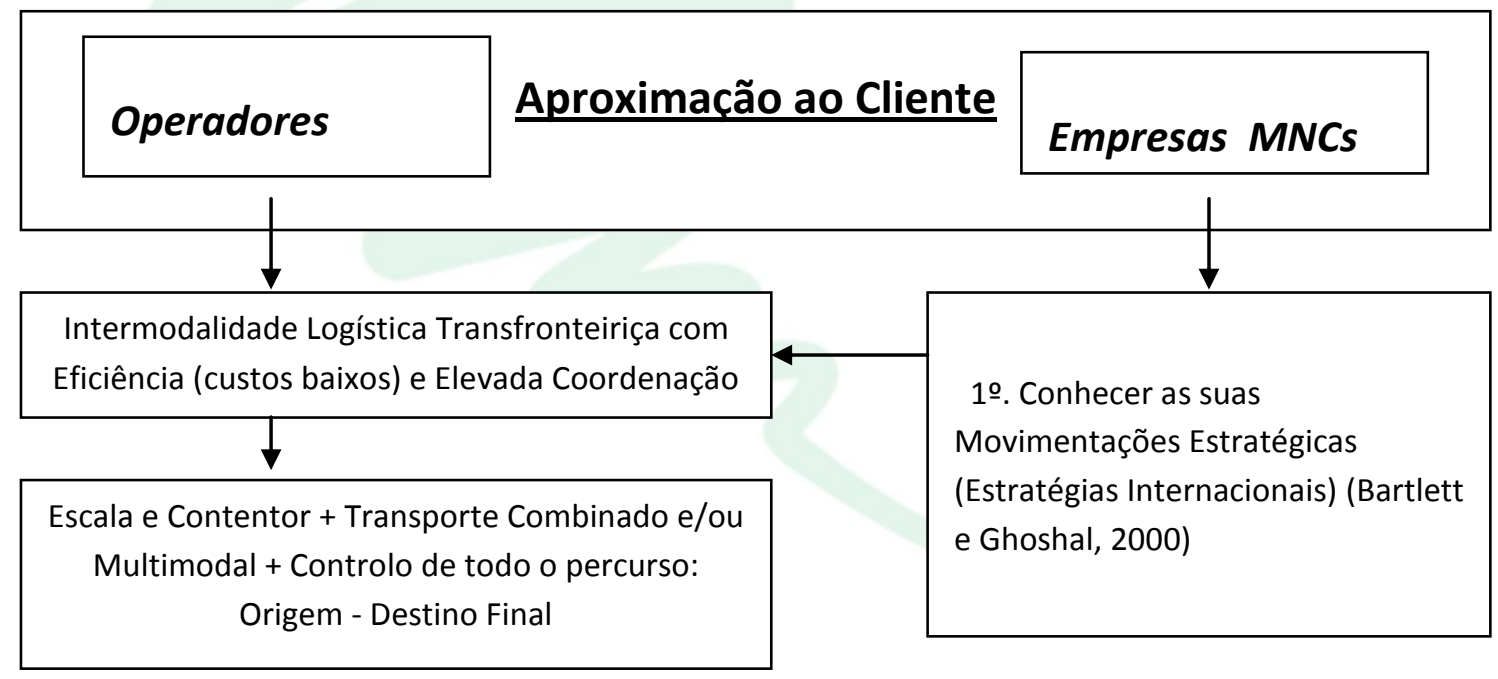

Fonte: Elaborada pelos autores.

As empresas logísticas buscam movimentações estratégicas importantes quer no sentido da eficiência pela compressão dos tempos e custos, quer no sentido da flexibilidade pela agilidade,

\footnotetext{
${ }^{4}$ Adiamento o mais a jusante e o mais tarde possível de actividades finais, como, p.ex., o embalamento.
} 
adaptabilidade e alinhamento com os clientes (Christopher \& Towill, 2001). Para alcançar estes desideratos, os grandes operadores, regra geral, procuram oferecer serviços cada vez mais integrados, incluindo transporte, armazenagem, stockagem e distribuição; procuram prestar serviços cada vez mais personalizados e serviços postponement; procuram oferecer pacotes integrados a preços mais baixos; procuram estabelecer acordos contratuais de fidelização com os seus clientes (e fornecedores) a prazos mais dilatados (acima de 5 anos); e também procuram aumentar a sua dimensão e massa crítica pela aquisição e/ou fusão de outras empresas ou através de alianças estratégicas em cooptição.

Por outro lado, as movimentações estratégicas das empresas MNCs produtoras e/ou distribuidoras podem ser afectadas ou mesmo determinadas pelo peso específico das actividades na sua competitividade. E neste aspecto é crescentemente determinante para as empresas que praticam negócios internacionais a relevância da logística assim como a compreensão da configuração e alcance das suas estratégias internacionais. A compreensão, por parte das empresas, do meio ambiente físico, do meio ambiente da tarefa e do meio ambiente social onde vão actuar, é imprescindível para a boa qualidade das suas decisões (Foster, 2007) e, por consequência, fundamental para o seu sucesso. Por definição, logística ${ }^{5}$ não é só transportes, armazenagem e gestão de stocks, como vulgarmente se entende, mas inclui, também, uma grande variedade de subactividades associados em função da extensão da cadeia de valor da empresa aos clientes e à cadeia de abastecimento (Bowersox \& Daugherty, 1987).

O conceito de gestão da cadeia de abastecimento ${ }^{6}$ aumenta o conceito económico de cadeia de valor (alguns dos métodos usados para estimar esse valor podem ser encontrados em Ballou (2006), passando a incluir fornecedores, instalações, centros de distribuição e consumidores. Um dos seus aspectos mais significativos é a ligação entre fornecedores e consumidores, envolvendo uma complexa interacção entre logística, sistemas e comportamento humano (Foster, 2007).

Este conceito mais alargado está reflectido quer nas definições de Mentzer et al. (2001), quer nas de Bozarth e Handfield (2007), onde a cadeia de abastecimento é definida como englobando todas as actividades associadas com o fluxo e a transformação dos bens, desde a extracção da matéria-prima até ao consumo pelo cliente final, assim como com o fluxo de informação relacionado. Nesse sentido, Mula, Poler, Garcia-Sabater e Lario (2006) apresentam diversos modelos (conceptuais e analíticos), para o correcto planeamento da cadeia de

\footnotetext{
${ }^{5}$ A logística é o processo de planeamento, implementação e controlo dos fluxos e armazenamento de matérias-primas, produtos acabados, semiacabados ou em curso e respectiva informação correlacionada, desde a origem ao consumidor final, em eficiência e em conformidade com as exigências dos clientes (Flint \& Kent, 1997).

${ }^{6}$ A gestão da cadeia de abastecimento corresponde ao aprofundamento da integração logística em cooperação e partilha de informação com as cadeias de valor de fornecedores e eventualmente clientes. É, portanto, um conceito logístico.
} 
abastecimentos. A gestão da cadeia de abastecimento visa, então, a integração e a melhoria do relacionamento de todas essas actividades, no sentido da organização obter uma vantagem competitiva sustentada, para o que a check list referida na Figura 2 contribui significativamente:

Figura 2- Check list do interface Logística-emrpesas.

\begin{tabular}{|c|c|}
\hline $\begin{array}{l}\bullet \\
\bullet \\
\bullet \\
\bullet \\
\bullet \\
\bullet \\
\bullet \\
\cdot \\
\cdot \\
\bullet \\
\bullet \\
\bullet \\
\bullet \\
\bullet \\
\bullet \\
\bullet \\
\bullet\end{array}$ & $\begin{array}{l}\text { Listagem de todos os produtos (Especialização) } \\
\text { Localização de clientes, pontos de armazenagem e pontos de fornecimento } \\
\text { Procura por produtos e por localização dos clientes } \\
\text { Custos e tarifas de transporte } \\
\text { Frequência do trânsito (entregas/saídas) } \\
\text { Custos de armazenagem. Custos de paragem. Tempos de espera } \\
\text { Dimensão dos transportadores por produto } \\
\text { Níveis de stockagem por localização, produto e método para o seu controlo } \\
\text { Tipos de encomendas por frequência, tamanhos, sazonalidade e conteúdo } \\
\text { Custos de processo e sua localização } \\
\text { Custos de capital. Avaliação dos investimentos correctos para infraestruturas. Rentabilidade destes Inv. } \\
\text { Objectivos de servir ao cliente } \\
\text { Equipamento, instalações e respectivas limitações de capacidade. Áreas de concessão e manuseamento } \\
\text { Padrões de distribuição } \\
\text { Serviços de alteração, reparação, incorporação aos produtos } \\
\text { Tempos e custos aduaneiros }\end{array}$ \\
\hline
\end{tabular}

Fonte: Adaptada de Bowersox e Daugherty (1987) e Langley, Allen e Colombo (2003).

No que respeita a uma estratégia para o mercado global, segundo Tallman (2001), as componentes essenciais são duas: a expansão internacional, vulgarmente conhecida como internacionalização; e a integração global, isto é, a estratégia de consolidar mercados internacionais e operações numa única entidade estratégica mundial, realçando a necessidade de coordenar actividades em múltiplos e diferentes mercados (Kogut, 1989). Como já referimos e na perspectiva dos negócios internacionais, os clientes dos portos portugueses são, principalmente, as empresas exportadoras nacionais, as empresas multinacionais, em regra detentoras de produtos próprios e os grandes operadores logísticos internacionais ${ }^{7}$ que actuam por conta das empresas nacionais ou multinacionais. Como conciliar, então, na óptica dos portos portugueses, a logística com a exportação e as estratégias internacionais das empresas (clientes)?

A relação que se estabelece entre os portos e as necessidades dos seus clientes tem implicações a dois níveis: ao nível do comércio internacional e ao nível logístico.

\footnotetext{
${ }^{7}$ Estes grandes operadores logísticos internacionais são também, na sua maioria empresas multinacionais, basicamente de serviços e que lidam com os produtos de outras empresas. Tratá-los-emos como operadores logísticos internacionais para se distinguirem das empresas multinacionais produtoras e/ou distribuidoras dos seus próprios produtos.
} 
Quanto às empresas exportadoras existem implicações ao nível do comércio internacional na medida em que aquelas têm especificidades ao nível dos produtos e dos mercados que servem, assim como das práticas administrativas, e ao nível logístico porque o porto deve estar administrativa e infraestruturalmente preparado e equipado para gerir com eficiência e eficácia os negócios que intermedeia. Como se nota na Figura 3, e em função do conhecimento que o porto tem dos seus clientes que exportam, o ajustamento do porto ao cliente faz-se pela especialização em produtos, mercados, tipos de barcos, áreas de concessão, acostagem, trabalho e manuseamento, conservação de equipamentos, tipologia de terminais de intermodalidade, fundura de calados, etc.

Figura 3- Empresas exportadoras nacionais e as principais implicações nos portos.

\begin{tabular}{|l|l|}
\hline $\begin{array}{l}\text { Ao nível do Comércio } \\
\text { Internacional }\end{array}$ & Ao nível da Logística \\
& - Interfaces Rodo/Ferro/Marítimo \\
- Comércio tipicamente & - Contentores. Zonas de parqueamento, manuseamento e reparação de \\
de sentido único & contentores \\
- Médias e/ou Pequenas & - Grupagem \\
Quantidades & - Rampas Ro - Ro \\
- Em regra FOB & - Especialização de Produtos \\
(Free-on-board) & - Equipamentos de Movimentação \\
- Especialização de & - Zonas de Stockagem (industrial, por paletes, frigorífica, etc.) e \\
Produtos & Distribuição \\
& - Zonas de pequenos Acabamentos e/ou Transformações em \\
& produtos/embalagens \\
& - Zonas de apoio Comercial, Administrativo e Financeiro \\
\hline
\end{tabular}

Fonte: Elaborada pelos autores.

Quanto às empresas multinacionais, a complexidade aumenta na medida em que, como já referimos, deve-se, em primeiro lugar, compreender a forma como se movimentam nos mercados globais, ou seja, identificar e conhecer a fundo as suas estratégias internacionais e os contornos que essas estratégias assumem. Percebidas estas, e adaptando o porto às implicações necessárias ao nível do comércio internacional e da logística, a gestão do relacionamento com o cliente, por parte do porto pode revelar-se mais eficiente e alinhado e por isso pode elevar o porto a parceiro fidelizado da multinacional ou dos operadores logísticos internacionais que actuam em seu nome. Ballou (2007) confirma esta ideia, ao referir que a colaboração e a coordenação, em conjunto com a confiança mútua, são os elementos mais importantes no aproveitar das oportunidades existentes nos mercados globais.

Nas abordagens tradicionais as MNCs são vistas como uma organização em que a sede central tem o papel decisivo, é o quartel-general (Ghoshal \& Nohria, 1989), ou a casa-mãe, que 
controla e coordena as suas subsidiárias espalhadas pelo mundo. Nas empresas que utilizam estratégias multinacionais, internacionais e globais (Bartlett \& Ghoshal, 1989), multidomésticas (Porter, 1986), o atributo da subsidiária é apenas local. O papel global e coordenador é desempenhado pela sede que é quem tudo decide, mas a organização das MNCs está a evoluir questionando o papel da sede como único centro de poder. Na medida em que a dispersão geográfica de actividades, através de subsidiárias, comporta uma relação tridimensional: com a casa-mãe, com as autoridades locais e com a rede local (Simões \& Nevado, 2001), alguns casos existem em que a subsidiária assume tal influência que passa a deter um poder regional sobre outras subsidiárias de países vizinhos fazendo emergir uma relação com a casa-mãe de centre-centre (Ghauri, 1990).

Deste modo algumas das subsidiárias no estrangeiro tornam-se centros estratégicos (Surlemont, 1998) com responsabilidades que ultrapassam as exclusivamente locais e controlam recursos que dependem doutras unidades (Forsgren \& Pahlberg, 1992). Para além disso a importância do papel das subsidiárias pode ser acrescido quando a casa-mãe resolve ir além da viabilização da subsidiária. A segunda fase do desenvolvimento duma subsidiária é dar-lhe a sustentabilidade, criar fundações, viabilizar (Birkinshaw \& Hood, 1997). Para este objectivo a subsidiária pode tornar-se uma especialista de produto, mas com a responsabilidade de ser the best in class entre todas as irmãs, ou pode tornar-se uma world mandate com relativamente elevada autonomia. Isto é, a subsidiária por mérito próprio faz melhor que as suas irmãs e, adicionalmente, procura oportunidades de negócio, desenvolvendo uma espécie de orientação empreendedora (Yamin, 2002).

No entanto a sede tem de reconhecer a capacidade para uma subsidiária ser algo mais do que mera executante das directrizes da casa-mãe. Esse reconhecimento só acontecerá se a subsidiária for capaz de, para além da relação estabelecida com a casa-mãe, souber criar laços de desenvolvimento relevantes com o mercado local e até com as outras subsidiárias dentro do grupo (Simões \& Nevado, 2001). E ao desenvolverem estas capacidades especiais em qualquer parte da cadeia de valor da empresa, a subsidiária está a tornar-se um centro de excelência (Simões \& Nevado, 2001) dentro do grupo, e como que rubrica um contrato de qualidade, desenvolvimento e expectativa elevada.

Portanto, e em resumo, pode dizer-se que a evolução da subsidiária passa por duas fases cruciais: a primeira que é a da afirmação, da viabilização, é a fase de pôr as coisas a funcionar, e a outra fase é a da sustentação (Birkinshaw \& Hood, 1997), e nesta a subsidiária terá de ser capaz,

Revista Ibero-Americana de Estratégia - RIAE, São Paulo, v. 8, n. 2, p. 135-160, jul./dez. 2009. 
com o tempo que tem, de criar factores de distintividade dentro do grupo e de ligação ao mercado exterior, nomeadamente local, para ganhar notoriedade e presença para o médio e longo prazo.

Por tudo isto, o porto poderá ter numa qualquer subsidiária um forte e leal parceiro e aliado duradouro, naquele mercado local servido pelo porto, se pela sua gestão contribuir para a excelência de desempenho da subsidiária dentro do seu próprio grupo. Para isso o primeiro passo é conhecer como se organiza estrategicamente a MNC e depois viabilizar da melhor maneira o desempenho da subsidiária (Birkinshaw \& Hood, 1997).

Proposição 1: O Porto ao acompanhar e colaborar activamente com as empresas potenciais clientes dos portos no sentido de adaptar infraestruturas e diferentes check lists de funções está a integrá-las com vantagem no seu hinterland ${ }^{8}$, mas está, também, a investir na viabilização e sustentabilidade da subsidiária junto da sede da multinacional e a contribuir para um processo de internacionalização mais avançado das empresas exportadoras.

Por outro lado, existem, basicamente, quatro estratégias internacionais ${ }^{9}$ que são utilizadas pelas empresas para orquestrar as suas diferentes actividades e/ou negócios em diferentes mercados: a estratégia multinacional (multidoméstica) ${ }^{10}$, a estratégia internacional, a estratégia global, e a estratégia transnacional (Bartlett \& Ghoshal, 1989, 2000). Como se pode ver na Figura 4, a primeira encerra, essencialmente, uma preocupação de adaptabilidade aos mercados locais, as duas seguintes organizam-se visando a maior eficiência, e a última tenta integrar a adaptabilidade com a eficiência e com a capacidade de, aprendendo em cada mercado local, disseminar esse conhecimento por toda a organização ${ }^{11}$.

\footnotetext{
${ }^{8}$ Área de influência e atractividade mais ou menos vasta e que pode albergar mais do que uma região ou país (Notteboom e Rodrigue, 2005)

${ }^{9}$ Existe uma outra estratégia internacional, a metanacional (Doz, Santos \& Williamson, 2001) que propõe uma abordagem diferente pelo que não a consideramos neste artigo.

${ }^{10}$ Por vezes chama-se à estratégia multinacional estratégia multidoméstica, termo que se refere à estratégia dirigida a cada país introduzida por Porter (1986). Embora existam algumas diferenças entre elas, não sendo, por isso, coincidentes, iremos tratá-las, por comodidade, como se o fossem.

${ }^{11}$ Para a maioria dos autores a exportação não é uma estratégia internacional, mas um processo, comum, de internacionalização e muito utilizada, como sabemos, pelas empresas portuguesas e crescentemente pelas empresas brasileiras.
} 
A Logística na Internacionalização dos Portos Marítimos

Figura 4- Resumo da gestão das actividades das empresas MNCs em função da Estratégia Internacional.

\begin{tabular}{|c|c|c|c|}
\hline $\begin{array}{l}\text { MULTINACIONAL/ } \\
\text { MULTIDOMÉSTICA }\end{array}$ & GLOBAL & INTERNACIONAL & TRANSNACIONAL \\
\hline $\begin{array}{l}\text { Descentraliza a cadeia } \\
\text { de valor (todo o } \\
\text { conjunto de } \\
\text { actividades) numa } \\
\text { lógica de se adaptar o } \\
\text { melhor possível às } \\
\text { características de cada } \\
\text { país em concreto. } \\
\text { Serve, basicamente, } \\
\text { mercados nacionais. }\end{array}$ & $\begin{array}{l}\text { A empresa } \\
\text { centraliza a } \\
\text { maior parte das } \\
\text { suas actividades } \\
\text { num país e } \\
\text { tipicamente } \\
\text { descentraliza } \\
\text { algum do } \\
\text { Marketing e } \\
\text { Serviço ao } \\
\text { Cliente. Serve o } \\
\text { globo como se } \\
\text { se tratasse dum } \\
\text { mercado único. }\end{array}$ & $\begin{array}{l}\text { A empresa } \\
\text { descentraliza parte } \\
\text { da cadeia de valor, } \\
\text { tipicamente as } \\
\text { operações relativas à } \\
\text { Produção. Serve o } \\
\text { mercado, por vezes, } \\
\text { regional e abastece e } \\
\text { abastece-se, em } \\
\text { regra, com a casa- } \\
\text { mãe e/ou outras } \\
\text { filiais. }\end{array}$ & $\begin{array}{l}\text { Descentraliza toda a } \\
\text { cadeia de valor, mas } \\
\text { tem uma preocupação } \\
\text { de servir o mercado } \\
\text { local e global, a partir } \\
\text { de cada fábrica, duma } \\
\text { forma eficiente, } \\
\text { adaptativa e } \\
\text { transferidora de } \\
\text { conhecimento. }\end{array}$ \\
\hline
\end{tabular}

Fonte: Adaptada de Bartlett e Ghoshal (1989; 2000).

As empresas que adoptam uma estratégia global focam-se num aumento de rentabilidade pelo aproveitamento dos efeitos da curva de experiência nomeadamente através da redução de custos. Adoptam uma estratégia de baixo custo e as suas actividades estão concentradas em poucas localizações favoráveis. Tendem a não adaptar os seus produtos e a sua estratégia de marketing às condições locais porque esta adaptação faz aumentar os custos, pois envolve séries de produção mais pequenas e duplicação de funções. Ao invés as empresas globais preferem lançar para os mercados de todo o mundo um produto estandardizado, usufruindo assim de todos os benefícios das economias de escala subjacentes à curva de experiência, usando, por isso, as suas vantagens de custo para suportar políticas de preço muito agressivas em todos os mercados. A empresa que adopta uma estratégia global é, em princípio, uma empresa que privilegia a eficiência, o custo baixo, a compressão dos custos e dos tempos. Tem, em regra, fornecimentos de larga escala e as suas subsidiárias espalhadas pelo mundo são tipicamente subsidiárias comerciais, estando as outras actividades maioritariamente concentradas na sede do grupo ou próximo, ou numa outra, mas única (ou quase) localização principal. Por isso, numa empresa que adopta uma estratégia global os seus produtos têm, em regra, um local (ou poucos) de origem. Os destinos desses produtos são, na maior parte das vezes, as filiais comerciais do grupo espalhadas por muitos e variados sítios. Porque em regra a MNC global tem muitas subsidiárias comerciais, não raramente uma, pelo menos, por país, 
esta MNC utiliza, por vezes, pontos de destino intermédio, em locais estratégicos, p.ex. Europa Holanda (Roterdão), onde se encontram grandes centros de armazenagem e distribuição, que concentram as saídas dos produtos para várias, mais do que uma, filiais comerciais de diferentes zonas e países.

Em termos dos transportes a empresa global, em regra, utiliza o transporte marítimo de longo curso da origem até ao ponto intermédio - porto - e deste, em regra, vai em transporte terrestre até ao destino intermédio, se o grande centro de armazenagem e distribuição não estiver localizado no próprio porto. Do destino intermédio até ao destino final a opção normalmente escolhida não é tão invariável, podendo ser efectuado por rodovia, ferrovia, ou marítimo de curta distância, em sistema modal ou combinado. No entanto existe alguma supremacia do transporte rodoviário.

As empresas que adoptam uma estratégia internacional tentam criar valor pela transferência de competências e produtos para mercados estrangeiros onde os competidores locais não detêm essas competências e produtos ou então detêm-nas apenas parcialmente. Tendem a centralizar as actividades de desenvolvimento na sede, contudo tendem, também, a estabelecer as actividades de marketing e produção em cada um dos principais países onde estão presentes, mas limitadamente, isto é, com elevado controlo por parte da sede sobre a estratégia de marketing e de produto daquelas subsidiárias, apesar de estas poderem fazer pequenas adaptações locais. Uma estratégia internacional faz sentido se uma empresa tiver uma competência ligada ao seu negócio principal, uma competência específica com valor, que não existe nos competidores locais e se a empresa enfrentar relativamente fracas pressões para a responsabilização local. Contudo quando as pressões para a responsabilização local são altas, as empresas que seguirem esta estratégia perdem para as empresas que enfocam na adaptação do produto e na estratégia de marketing aos consumidores, às necessidades e condições locais. Por outro lado, devido à duplicação de lugares para a produção, as empresas que adoptam uma estratégia internacional tendem a confrontar-se com custos operacionais elevados, o que implica uma permanente pressão da gestão local e da sede para a redução de custos. Se a empresa adopta uma estratégia internacional estamos perante uma empresa que se preocupa também com eficiência em termos de tempos e custos baixos, mas que tem uma presença no mercado diferente da empresa global. Normalmente, e por consequência do tipo de produto ou do tipo de negócio, a empresa descentraliza toda a cadeia de valor (com excepção habitual da I\&D e do aprovisionamento principal - central de compras) e promove a eficiência replicando a casa-mãe nas unidades regionais, nacionais ou locais, cumprindo rigorosamente as políticas definidas pela sede, utilizando a central de compras da casa-mãe, e aplicando os excedentes financeiros segundo as

Revista Ibero-Americana de Estratégia - RIAE, São Paulo, v. 8, n. 2, p. 135-160, jul./dez. 2009. 
regras estabelecidas também superiormente. Neste sentido a empresa internacional utiliza desde a origem, em regra, o transporte marítimo internacional de longo curso, e tem como destino final os vários pontos do mundo onde se encontram as suas fábricas. Do porto para as fábricas são habitualmente utilizados transportes rodoviários.

Proposição 2: Ir ao encontro de uma empresa que se movimenta numa lógica de eficiência, associada em regra a estratégias corporate globais e/ou internacionais, as logísticas de entrada e de saída do porto deverão ser de elevada exigência, com compressão de todos os custos e tempos. Esta compressão deverá incluir o cross-docking ${ }^{12}$ e também sistemas de informação avançados (EDI e/ou outros), de forma a conseguir a administração mais eficiente possível de todas as inter-relações entre espaços - inventariação - custos - tempo.

Por outro lado ainda, as empresas que adoptam uma estratégia multinacional/multidoméstica orientam-se para a obtenção do máximo de responsabilização local. Tal como as empresas que adoptam uma estratégia internacional, as que adoptam uma estratégia multidoméstica também tendem a transferir competências e produtos desenvolvidos em casa para os mercados estrangeiros. Contudo, ao contrário da estratégia internacional, as empresas que utilizam a estratégia multidoméstica adaptam quer o produto oferecido, quer a sua estratégia de marketing, às diferentes condições dos países locais/hospedeiros. Concomitantemente tendem, também, a estabelecer uma série de actividades da cadeia de valor, incluindo a produção, o marketing e a I\&D em cada um dos principais mercados onde fazem negócios.

Como resultado estas empresas têm alguma incapacidade, em geral, de realizar e criar valor a partir dos efeitos associados à curva de experiência, mas normalmente têm elevados custos de estrutura. Outro aspecto associado com esta estratégia é o de que muitas empresas multidomésticas desenvolveram-se no sentido duma federação descentralizada na qual cada subsidiária nacional funciona duma maneira relativamente autónoma. Como resultado ao fim de algum tempo as empresas multidomésticas começam a perder alguma capacidade para transferir competências, e produtos derivados das competências específicas da sede, para as várias subsidiárias nacionais pelo mundo fora.

A empresa que adopta uma estratégia multinacional ou multidoméstica é uma empresa que privilegia a relação próxima com o mercado local procurando adaptar-se a ele o mais possível, pelo

\footnotetext{
12 Cross Docking é uma operação em que as mercadorias passam nos armazéns directamente do cais de entrada para o cais de saída, sem armazenamento e com operações de manuseamento reduzidas ao mínimo (Langley, Jr. et al, 2003)
} 
que não tem enfoque elevado nas relações com outros mercados pela via, por exemplo, da exportação. São empresas cujas subsidiárias podem importar da casa-mãe, em regra, algumas matérias-primas, ou produtos semiacabados, e a internacionalizarem-se a partir dos países locais de destino fazem-no pela exportação, mas em pequenas quantidades e para locais próximos. A existir este comércio, pela proximidade e pela sua quantidade, é efectuado essencialmente pela via terrestre.

Proposição 3: Aproximar o porto dum cliente que adopta estratégias de adaptabilidade significa que a logística de entrada do porto deverá deter uma grande capacidade de handling dos materiais, minimizando eventuais prejuízos e melhorando a qualidade, embalamento e/ou apresentação dos produtos. Por outro lado, a logística de saída deverá proporcionar uma resposta eficaz, em termos de processo, a qualquer tipo de ordem (incluindo serviços, reparações e pequenas alterações de produtos), e também uma rápida entrega e distribuição dos produtos aos clientes. Neste caso, sem nunca abdicar da compressão dos tempos (característica sempre presente na actividade logística), o porto deverá ainda proporcionar, atempadamente, um serviço de 'postponement' de elevada qualidade e diversificação.

As três estratégias internacionais referidas nas proposições anteriores, a global, a internacional e a multinacional, têm implicações diferentes no comércio internacional, conforme se pode ver na Figura 5, no entanto a quarta estratégia internacional, a transnacional, tenta conjugar e integrar o que cada uma das outras três tem de mais positivo.

Revista Ibero-Americana de Estratégia - RIAE, São Paulo, v. 8, n. 2, p. 135-160, jul./dez. 2009. 
Figura 5- Implicações-resumo no Comércio Internacional das MNCs em função das suas Estratégias Internacionais .

\begin{tabular}{|c|c|}
\hline $\begin{array}{l}\text { ESTRATÉGIA } \\
\text { INTERNACIONAL } \\
\text { (BARTLETT \& GHOSHAL, } \\
\text { 1989) }\end{array}$ & COMÉRCIO INTERNACIONAL \\
\hline Global & $\begin{array}{l}\text { - Exportação do país de origem para vários (muitos) países } \\
\text { - Predominância de comércio internacional de sentido único } \\
\text { - Grandes quantidades (escala) } \\
\text { - Tipicamente empresas do Oriente e BRIC (Brasil, Rússia, Índia, China) }\end{array}$ \\
\hline Internacional & $\begin{array}{l}\text { - Exportação dos países onde se situam as filiais (produtivas) para outros } \\
\text { países onde se situam outras filiais (produtivas e/ou Mkt) } \\
\text { - Predominância de comércio internacional de sentido de ida e volta } \\
\text { - Grandes quantidades (escala) } \\
\text { - Tipicamente empresas dos EUA e Europa e com filiais em países BRIC }\end{array}$ \\
\hline $\begin{array}{l}\text { Multinacional / } \\
\text { Multidoméstica }\end{array}$ & $\begin{array}{l}\text { - Havendo exportação pelas filiais, é, em regra, para países próximos } \\
\text { - Pequenas/médias quantidades } \\
\text { - Tipicamente empresas da Europa }\end{array}$ \\
\hline
\end{tabular}

Fonte: Elaborada pelos autores.

Bartlett e Ghoshal (1989, 2000) argumentam com a estratégia transnacional por considerarem que na realidade actual as condições de competitividade são tão intensas que para sobreviver no mercado global as empresas devem explorar as economias de escala baseadas na experiência, assim como devem transferir competências distintivas dentro do grupo, mas devem-no fazer dando muita atenção às pressões para a responsabilização local. As competências distintivas podem residir, aparecer ou desenvolverem-se em qualquer das subsidiárias que a empresa detenha em qualquer sítio do mundo. Assim sendo, o fluxo de competências e produtos não deve ser de sentido único da sede para as subsidiárias no estrangeiro, como nas empresas que adoptam uma estratégia internacional, mas o fluxo também deve ser no sentido da subsidiária estrangeira para o país de origem e duma subsidiária estrangeira para outra sua irmã - um processo a que os autores chamam de aprendizagem global.

A empresa que adopta uma estratégia transnacional é uma empresa com um grande potencial de compromisso com os mercados locais e com os mercados globais, e com uma grande abertura 
para a aprendizagem e a transferência do conhecimento adquirido em qualquer parte do mundo. Neste sentido é uma empresa que tenta integrar as três dimensões estratégicas referidas: eficiência, adaptabilidade e aprendizagem e disseminação do conhecimento aprendido.

Assim sendo, o comércio internacional destas empresas pode ter origem em vários e diferentes países, e pode igualmente ter como destino, quer destinos finais, quer destinos intermédios, como são grandes centros de armazenagem e distribuição, filiais antenas, projectos chave-na-mão, etc. Da origem para o destino intermédio (porto) a empresa, em regra, utiliza o transporte marítimo de curto, médio ou longo curso. Do porto para o efectivo destino intermédio é habitualmente utilizado o transporte terrestre. Do destino intermédio para o destino final qualquer das modalidades são utilizadas, a rodovia, a marítima de média distância, e a ferrovia, mas o transporte terrestre continua a ser o preferido. Neste sentido a estratégia transnacional, no que respeita ao comércio internacional, abarca o que de essencial existe em cada uma das outras estratégias (conforme Figura $5)$.

Ao investir na relação com o cliente da maneira referida o Porto pode contribuir para a competitividade da empresa que serve de três formas:

Contribuindo para que a empresa consiga estar presente nos mercados internacionais a preços mais baixos que a concorrência (Hitt et al., 2005), preços esses que, em regra, são obtidos pela capacidade da empresa em incorporar nos produtos custos directos e indirectos mais reduzidos que os seus concorrentes, i.e., a empresa baixa os custos quando encontra formas de dar mais eficiência às actividades que criam valor;

contribuindo para que a empresa consiga levar para o mercado produtos que pela sua distinção, unicidade, qualidade e adaptabilidade são percebidos pelos seus clientes como diferenciadores de todos os outros, e por isso mesmo superiores à concorrência (Kotler \& Keller, 2006).

ou contribuindo para que a empresa consiga um compromisso difícil, mas compensador, entre o custo muito baixo, mesmo não sendo o mais baixo do mercado, e a diferenciação percebida como elevada, mesmo não sendo única (Hitt et al., 2005).

A integração do porto na cadeia de valor ou na fileira de negócio da empresa obriga a que o porto ofereça os serviços e/ou actividades desejadas pela empresa multinacional e que o faça no respeito pelas estratégias de negócio ou corporate da empresa. Isto é, p.ex., se a empresa busca a eficiência, deve o porto agir em conformidade, se a empresa privilegia sobretudo a adaptabilidade aos mercados locais, deve o porto igualmente dotar-se de subactividades que deem confiança aos seus clientes e contribuam para a sua competitividade. Assim sendo, as duas próximas proposições tentam retratar a situação das duas situações em que a adaptabilidade tem importância, não obstante na estratégia corporate transnacional a adaptabilidade conviver com a eficiência e a aprendizagem.

Revista Ibero-Americana de Estratégia - RIAE, São Paulo, v. 8, n. 2, p. 135-160, jul./dez. 2009. 
A Logística na Internacionalização dos Portos Marítimos

Proposição 4: Aproximar o Porto dum cliente que segue uma estratégia transnacional, significa que o porto detenha subactividades que simultaneamente sejam eficientes, mesmo que não sejam as de preço mais baixo, e com grande capacidade de adaptabilidade aos desejos dos clientes e dos mercados locais, em termos de rapidez, qualidade, diferenciação e capacidade de inovação, mesmo que não sejam os melhores.

De realçar, então, como vimos, que compreender cada cliente potencial conhecendo as suas movimentações estratégicas, é um factor de grande importância para dotar os portos das infraestruturas necessárias ao alinhamento estratégico com os seus clientes e que estão sistematizadas na Figura 6.

Figura 6 - Necessidades infraestruturais logísticas (resumo) dos portos portugueses em função das estratégias internacionais dos clientes.

\begin{tabular}{|c|c|c|c|c|}
\hline $\begin{array}{l}\text { NECESSIDADES INFRAESTRUTURAIS } \\
\text { LOGÍSTICAS }\end{array}$ & GLOBAL & INTERN. & MULTINAC. & TRANSN. \\
\hline - Longo curso (marítimo) & $\mathbf{x}$ & $\mathbf{x}$ & & \\
\hline - Pequeno, Médio e Longo curso (marítimo) & & & & $\mathbf{X}$ \\
\hline - Contentores + Equipamento Movimentação & $\mathbf{x}$ & $\mathbf{x}$ & $\mathbf{x}$ & $\mathbf{x}$ \\
\hline $\begin{array}{l}\text { - Portos com calado fundo (-12mts). Cais de } \\
\text { acostagens }\end{array}$ & $\mathbf{x}$ & $\mathbf{x}$ & & $\mathbf{X}$ \\
\hline - Interface de Transportes (multimodais) & $\mathbf{x}$ & $\mathbf{x}$ & $\mathbf{x}$ & $\mathbf{X}$ \\
\hline - Rampas Ro - Ro & $\mathbf{x}$ & $\mathbf{x}$ & & $\mathbf{X}$ \\
\hline $\begin{array}{l}\text { - Zona de Parqueamento de Contentores em trânsito. } \\
\text { Zona de parqueamento de vazios. Zona Manutenção } \\
\text { de Contentores }\end{array}$ & $\mathbf{x}$ & & $\mathbf{x}$ & $\mathbf{X}$ \\
\hline $\begin{array}{l}\text { - Zona para Stockagem, Armazenamento e } \\
\text { Distribuição (de longa duração) }\end{array}$ & $\mathbf{x}$ & & $\mathbf{x}$ & $\mathbf{x}$ \\
\hline $\begin{array}{l}\text { - Zona para Stockagem, Armazenamento e } \\
\text { Distribuiçãa (de curta duração). Capacidade de } \\
\text { elevada rotação }\end{array}$ & $\mathbf{x}$ & $\mathbf{x}$ & $\mathbf{x}$ & $\mathbf{X}$ \\
\hline
\end{tabular}

Revista Ibero-Americana de Estratégia - RIAE, São Paulo, v. 8, n. 2, p. 135-160, jul./dez. 2009. 
- Zona para Acabamentos e/ou Transformações de Produtos

Fonte: Elaborado pelos autores

O alinhamento estratégico com os clientes, é, também, um factor de grande interesse para poder desenvolver laços de solidariedade empresarial (Brown, Lamming, Bessant, \& Jones, 2006) e negocial com subsidiárias locais de empresas multinacionais, que podem ser as grandes aliadas dos portos junto das respectivas casas-mãe (Simões \& Nevado, 2001). Pode ser, de igual forma, um factor de vantagem competitiva, porque a aproximação personalizada ao cliente feita a esse nível institucional cria verdadeiras embaixadas de relacionamento e parceria que podem ajudar o porto no alargamento do hinterland para outras zonas onde se movimentam as multinacionais (p.ex. zona de Madrid para os portos portugueses). Pode ser igualmente importante porque esse investimento em conhecimento e relacionamento dota o porto de uma visão abrangente dos negócios e dos mercados globais tocados pelos seus clientes multinacionais, permitindo-lhe avaliar com maior racionalidade e rentabilidade os investimentos a realizar e as parcerias necessárias a desenvolver com outros operadores logísticos (Fleury, Wanke, \& Figueiredo, 2000), concorrentes ou não. E por último, pode ser também de determinante importância, se através disso o porto conseguir influenciar as multinacionais a interceder a seu favor junto dos grandes operadores logísticos internacionais que já sejam seus parceiros. Em suma, o porto necessita de ser competitivo, o que significa oferecer propostas de valor acrescentado aos seus clientes e preferencialmente de valor superior à média que a indústria oferece (Hitt et al., 2005), enfatizando a cooperação.

Proposição 5: Ser competitivo neste mercado é fazer os investimentos correctos, adicionar valências distintivas a outros parceiros, integrar redes de intermodalidades que permitam oferecer serviços o mais completos possíveis e/ou integrar, tendencialmente, parcerias com operadores logísticos internacionais.

Revista Ibero-Americana de Estratégia - RIAE, São Paulo, v. 8, n. 2, p. 135-160, jul./dez. 2009. 


\section{SÍNTESE CONCLUSIVA}

Em síntese, as empresas que praticam negócios internacionais com os portos não têm comportamentos iguais, pois assentam os seus objectivos em estratégias corporate internacionais diferentes. Assim sendo as infraestruturas portuárias, as actividades realizadas pelos portos e o comportamento competitivo destes beneficiam com uma aproximação aos seus clientes de forma desigual em função das movimentações estratégicas internacionais daqueles. Este alinhamento estratégico dos portos com os seus clientes na prossecução duma maior competitividade do porto pode dirigir a gestão deste para formas mais eficientes e diferenciadoras de logística de entrada e de saída, mas também na conquista de maior hinterland.

A prossecução de maior competitividade do porto, como pretendemos evidenciar, deve associar-se, igualmente, a um comportamento activo dos portos junto das empresas nacionais exportadoras e das empresas multinacionais, sejam subsidiárias ou casas-mãe. Esse comportamento activo dos portos ganhará maior eficácia ainda se efectuado, também, junto dos grandes operadores logísticos internacionais, alguns dos quais simultaneamente multinacionais. O sentido da sedução do porto a estes seus importantes clientes, pela logística e pela correcta interpretação das movimentações estratégicas, é conseguir incorporar as suas actividades na cadeia de valor daqueles. Se a quota-parte de trabalho que pode caber aos portos puder ser incorporada com vantagem no objectivo tendencial e crescentemente perseguido pelos operadores logísticos internacionais de domínio competitivo de todo o percurso da mercadoria desde a origem ao destino, o porto tornar-seá bastante mais competitivo, integrando-se numa rede, também ela competitiva, de aliança com vários agentes logísticos.

Em conclusão, pode-se dizer que através da modernização dos portos e da criação nesses portos de infraestruturas logísticas adequadas ao tipo dos seus clientes, Portugal e Brasil, aproveitando a frente marítima atlântica comum, poderão, também, tornar-se mais competitivos e melhorar a sua posição estratégica, promovendo plataformas com capacidade de gerar valor acrescentado para os dois países.

Revista Ibero-Americana de Estratégia - RIAE, São Paulo, v. 8, n. 2, p. 135-160, jul./dez. 2009. 


\section{REFERÊNCIAS}

Ballou, R. H. (2004). Business logistics: supply chain Management (5th ed.). New Jersey: Pearson Prentice Hall.

Ballou, R. H. (2006). Revenue estimation for logistics customer service offerings. The International Journal of Logistics Management, 17(1), 21-37. http://dx.doi.org/10.1108/09574090610663419

Ballou, R. H. (2007). The evolution and future of logistics and supply chain management. European Business Review, 19(4), 332-348. http://dx.doi.org/10.1108/09555340710760152

Bartlett, C. A., \& Ghoshal, S. (1989). Managing across borders: the transnational solution. Boston: Harvard Business School Press.

Bartlett, C. A., \& Ghoshal, S. (2000). The transnational management: text, cases and readings in cross-border management. New York: McGraw-Hill International.

Birkinshaw, J., \& Hood, N. (1997). An empirical study of development processes in foreign-owned subsidiaries in Canada and Scotland. Management International Review, 37(4), 339-364.

Boyer, R. (1998). As palavras e as realidades. In S. Cordellier (Org.), A globalização para lá dos mitos (pp. 19-61). Lisboa: Bizâncio.

Bowersox, D., Closs, D., \& Stank, T. (2000). Ten mega-trends that will revolutionize supply chain logistics. Journal of Business Logistics, 21(2), 1-16.

Bowersox, D., \& Daugherty, P. (1987). Emerging patterns of logistical organization. Journal of Business Logistics, 8(1), 46-60.

Bozarth, C., \& Handfield, R. (2007). Introduction to operations and supply chain management (2nd ed.). New Jersey: Pearson Prentice Hall.

Brown, S., Lamming, R., Bessant, J., \& Jones, P. (2006). Administração da produção e operações. Rio de Janeiro: Campus.

Chopra, S., \& Meindl, P. (2007). Supply chain management - strategy, planning, and operation (3rd ed.). New Jersey: Pearson Prentice Hall.

Christopher, M., \& Towill, D. (2001). An integrated model for the design of agile supply chains. International Journal of Physical Distribution \& Logistics Management, 31(4), 235-246. http://dx.doi.org/10.1108/09600030110394914

Revista Ibero-Americana de Estratégia - RIAE, São Paulo, v. 8, n. 2, p. 135-160, jul./dez. 2009. 
Doz, Y., Santos, J., \& Williamson, P. (2001). From global to metanational: how companies win the knowledge economy. Boston: Harvard Business School Press.

Fawcett, S. E., \& Magnan, G. M. (2002). The rhetoric and reality of supply chain integration. International Journal of Physical Distribution \& Logistics Management, 32(5), 339-361. http://dx.doi.org/10.1108/09600030210436222

Fleury, P. F., Wanke, P., \& Figueiredo, K. F.(Org.). (2000). Logística empresarial: a perspectiva brasileira. São Paulo: Atlas.

Flint, D., \& Kent, J. L. (1997). Perspectives on the evolution of logistics thought. Journal of Business Logistic, 18(2), 15-29.

Forsgreen, M., \& Pahlberg, C. (1992). Subsidiary influence and autonomy in international firms. Scandinavian International Business Review, 1(3), 41-51.

http://dx.doi.org/10.1016/0962-9262(92)90004-P http://dx.doi.org/10.1016/0962-9262(92)90010-4

Foster, S. T. (2007). Managing quality: integrating the supply chain (3rd ed.). New Jersey: Pearson Prentice Hall.

Ghauri, P. N. (1990). Emergence of new structures in Swedish multinationals. Advances in International Comparative Management, 4, 261-273.

Ghoshal, S., \& Nohria, N. (1989). Internal differentiation within multinational corporations. Strategic Management Journal, 10, 323-337.

http://dx.doi.org/10.1002/smj.4250100403

Hitt, M., Ireland, R., \& Hoskisson, R. (2005). Strategic management, competitiveness and globalization. Mason: South-Western College.

Kogut, B. (1989). A note on global strategies. Strategic Management Journal, 10, 383-389. http://dx.doi.org/10.1002/smj.4250100407

Kotler, P., \& Keller, K. (2006). Marketing management (12th ed). Upper Saddle River: Pearson Prentice Hall.

Langley, Jr, C., Allen, G., \& Colombo, M. (2003). Third-party logistics study - results and findings of the 2003ht Annual Study. Detroit: Ernst \& Young.

Levitt, T. (1983). The globalization of markets. Harvard Business Review, 61(3), 92-102. 
Mateus, A. (2009). Portugal tem de se virar novamente para o mar. Transportes em revista, 7(79), 32-37.

Menezes, J. (2000). O serviço de cadeias logísticas marítimas em portugal, avaliação de desempenho. Tese de Doutorado em Organização e Gestão de Empresas, Instituto Superior de Ciências do Trabalho e da Empresa, Instituto Universitario de Lisboa, Lisboa.

Mentzer, J., Dewitt, W., Keebler, J., Min, S., Nix, N., Smith, C., \& Zacharia, Z. (2001). Defining supply chain management. Journal of Business Logistics, 22(2), 1-25.

http://dx.doi.org/10.1002/j.2158-1592.2001.tb00001.x

Mula, J., Poler, R., García-Sabater, J. P., \& Lario, F. C. (2006). Models for production planning under uncertainty: a review. International Journal of Production Economics, 103, 271-285 http://dx.doi.org/10.1016/j.ijpe.2005.09.001

Ohmae, K. (1990). The borderless world: power and strategy in the interlinked economy. London: Collins.

Prahalad, C., \& Ramaswamy, V. (2000). Como incorporar as competências do cliente. HSM Management, 4(20), 42-52.

Porter, M. E. (1986). Competition in global industries: a conceptual framework. In M. E. Porter (Ed.), Competition in global industries (pp. 15-60). Boston: Harvard Business School Press.

Simões, V. C., \& Nevado, P. (2001). MNC centres of excellence stemming from acquisitions: long evolutionary paths or capturing opportunities? EIBA Annual Conference, 27 (pp. 34-61). Paris, FR.

Surlemont, B. (1998). A typology of centres within multinational corporations: an empirical investigation. In J. Birkinshaw \& N. Hood (Eds.), Multinational corporate evolution and subsidiary development (pp. 162-188). London: Macmillan.

Tallman, S. (2001). Global strategic management. In M. Hitt, R. Freeman \& J. Harrison (Eds.), The Blackwell handbook of strategic management (pp. 464-490). Malden: Blackwell.

Tichy, N., Brimm, M., Charan, R., \& Takeuchi, H. (1993). Leadership development as a lever for global transformation. In V. Pucik, N. M. Tichy \& C. K. Barnett (Eds.), Globalizing management: creating and leading the competitive organization (pp. 47-61). New York: Wiley.

Yamin, M. (2002). Subsidiary entrepreneurship and the advantage of multinationality. In V. Havila, M. Forsgren \& H. Hakansson (Eds.), Critical perspectives on internationalisation (pp. 133-150). New York: Pergamon.

Revista Ibero-Americana de Estratégia - RIAE, São Paulo, v. 8, n. 2, p. 135-160, jul./dez. 2009. 


\section{Recebido: 11/05/09}

Aprovado: 03/08/09

Revista Ibero-Americana de Estratégia - RIAE, São Paulo, v. 8, n. 2, p. 135-160, jul./dez. 2009. 